\title{
Reseña de Arellano, Ignacio y Menén- dez Peláez, Jesús (eds.), La imagen de la autoridad y el poder en el teatro del Siglo de Oro, New York, IDEA, 2016, 204 pp. ISBN 978-1-938795-24-4
}

\author{
Roser López Cruz \\ King's College London \\ REINO UNIDO \\ roser.lopez_cruz@kcl.ac.uk
}

[Hipogrifo, (issn: 2328-1308), 5.1, 2017, pp. 507-511]

Recibido: 17-02-2017 / Aceptado: 16-03-2017

DOI: http://dx.doi.org/10.13035/H.2017.05.01.34

Es de sobra conocida la relevancia que en el siglo XVII gozan las nociones de teatro y de poder -difícilmente desvinculadas, pues tan operativo era el poder del teatro como el teatro del poder en la cultura por antonomasia de las apariencias y la espectacularidad. En torno a estos dos ejes giran los trabajos reunidos en este volumen, que reflexionan acerca de la autoridad y el poder a través de un variado muestrario de imágenes, ideas y cauces de su ejercicio en y a través del teatro, abarcando diversos ámbitos y niveles que necesariamente atraviesan estas nociones, pero manteniendo un hilo conductor a través de los distintos artículos: el poder como control social y político, ya en plena operatividad, ya contestado y problematizado. En cada uno de los estudios se alternan distintas perspectivas analíticas sobre el tema, ilustrándolas con obras que prueban al tiempo el perspectivismo propio desde el cual abordaban los escritores del XVII estas cuestiones. De hecho, una de las constantes que se percibe en los trabajos aquí reunidos es la diversidad de tratamientos y soluciones -en ocasiones contradictorias entre sí- que proponen a un mismo asunto o problema cada una de las piezas del corpus de los ejemplos, perteneciendo incluso al mismo autor.

Si la institución (o instituciones) del poder es axial en la cultura del XVII y pilar de la sociedad y la política, los dramaturgos -así como escritores de otros géneros, literarios o históricos- no son ni mucho menos mero transmisores de este ni sirven a la dirección monolítica de la sociedad y la cultura. En cambio, exploran, cuestionan, extreman y subvierten las causas y consecuencias de todos estos resortes y cauces del poder, si bien todos convergen en la importancia del control de uno mismo como base de un poder efectivo. Esta dinámica se hace evidente 
en los diez casos de estudio reunidos en este volumen, pero no solo. También se aporta una mirada al plano diacrónico, señalando los cambios que se producen en los intereses, preocupaciones y, en definitiva, en la mentalidad a lo largo del siglo, tendente a la secularización de todas las instituciones del poder, lo que revela la instrumentalización del imaginario que lo constituye. A esto contribuyen los corpus de piezas teatrales que motivan e ilustran los estudios, si bien en ocasiones resulta confuso situarlas cronológicamente, debido a la falta de señalización de las fechas.

Abre el volumen el trabajo de Arellano, que se acerca al mito de la hermosa judía que absorbió la atención del rey Alfonso VIII, distrayéndolo de su deber. Tras dar unas breves pinceladas sobre el origen y desarrollo de esta figura en el imaginario histórico colectivo, Arellano compara las versiones de Lope y la posterior de Lanini, prestando especial atención a cuestiones genéricas que determinarán la relevancia de la figura en la trama. Se descubre así que, si bien es central en la obra del Fénix, dando en un fin trágico, en la propuesta de Lanini, con el énfasis puesto exclusivamente sobre la conducta y el comportamiento del rey, la judía queda relegada a un segundo plano, instrumentalizada para el fin de ejemplaridad. Esta preocupación del control del rey sobre sus pasiones y afectos será tema de base en otras obras -que, en principio, versan sobre asuntos distintos-, que estudiarán Lauer, Rull, Suárez Miramón y Vega García-Luengos.

No obstante, el vencimiento y control sobre uno mismo en pos de un bien que trasciende al individuo no es tarea del rey solamente. González-Barrera indaga sobre el tema del honor en el XVII, señalando la importancia del control de la mujer, ya sea por ella misma, ya sea por el padre o el marido (que viene a ser lo mismo), como depositaria de la honra familiar. Tras un repaso histórico de la figura del adulterio desde el Derecho romano hasta la sociedad de la Contrarreforma, en el que destaca la vinculación especial de esta falta a la mujer como potencial introductora de un linaje alterado (adulterado), González-Barrera repara en las circunstancias legales y sociales concretas del XVII, y en la distancia de la ficción planteada sobre las tablas - de vehementes y sangrientos asesinatos justicieros - sobre la realidad - donde no había tantos crímenes de honra como casos denunciados. De nuevo, parece que se plantea una instrumentalización, si bien en este caso para gusto de la audiencia, como el mismo Lope indicó, tal vez por sus efectos catárticos.

A vueltas con el comportamiento de reyes, Lauer reúne aquí cinco dramas que tratan la figura del rey Sebastián, analizando el modelo heroico que se propone en cada una de ellos y revelando lo que parece ser una evolución, así como avanza el siglo. De un rey temerario, irracional y orgulloso - que Lauer identifica con el modelo homérico - se pasa a un retrato más pulido de arrebatos y arrojos, más prudente y más preocupado por las consecuencias -que Lauer asocia al modelo virgiliano. El estudioso, en este caso, se limita a mostrar los datos y su propio análisis, sin conclusiones de mayor alcance que vinculen esta evolución al cambio de los tiempos y a la visión y expectativas que la sociedad tenía del monarca y sus funciones. Sí señala, y es interesante mencionarlo aquí, que aquellas obras que retratan al rey Sebastián como llevado de pasiones y vehemencia, introducen como contrapeso a 
la figura de Felipe II, aunque no queda claro si esto sirve a propósitos panegíricos o simplemente ejemplares.

También sobre modelos heroicos versa el siguiente artículo, si bien indagando sobre otro tipo de heroísmo, enmarcado en un cauce distinto de control social: el religioso. Menéndez Peláez aprovecha este espacio para presentar el proyecto que dirige, "Los jesuitas y el teatro del siglo de oro», que comprende desde la compilación de los manuscritos de piezas teatrales didácticas de los colegios jesuitas hasta la edición de los textos y volcado de estos en una plataforma digital de acceso abierto. Aquí, no obstante, se centra en el aspecto de la «propaganda ideológica» de estas piezas, lo que define como los pilares cristianos que rigen el programa docente de la Compañía de Jesús. Estos son fácilmente detectables en la dramaturgia - de carácter didáctico - que desarrollaron, lo que Menéndez Peláez explora en un corpus de dramas hagiográficos, que presentan modelos de fortaleza y de renuncia, de firmeza en la fe y de gracia divina, siendo al tiempo modelos verosímiles.

El control de uno mismo como medio de vencimiento trascendental es de nuevo centro en este artículo, que parte de unos versos de Calderón que parecieran, en principio, sugerir una ideología de equiparación de poderío militar y justicia. Rull, suspicaz ante este planteamiento de La vida es sueño, hace un repaso por los dramas calderonianos, analizando la ideología tras las armas y el poder. Examinando los contextos y situaciones dramáticas en que Calderón inserta tales aserciones, Rull prueba la vinculación de la noción de vencimiento con la tradición estoicosenequista, que parte del control sobre uno mismo como medio del verdadero y legítimo poder. De forma algo menos orgánica, Andreia Sambrian propone un repaso por dos obras de argumento transilvano que exploran diversas cuestiones sobre la autoridad y el poder en un contexto político y social alejado de la realidad de la España del XVII. No obstante, si bien muy informativo -e ilustrativo- sobre cuestiones como el linaje, los fundamentos de la organización social o la lealtad, el trabajo opta por describir y explicar los casos planteados sin un foco claro de análisis.

Saliéndose del género estrictamente dramático, Santa Aguilar estudia la teatralidad en dos episodios cervantinos paralelos, y cómo en virtud de esta los episodios se resuelven con desenlaces sorprendentes, que juegan con el horizonte de expectativas del lector. Los dos episodios que escoge son el de las bodas de Camacho del Quijote y el de las bodas de Daranio y Silveria de La Galatea. En la lógica de la ostentación, la apariencia y la teatralidad que se generan en estos banquetes celebrativos - que incluyen danzas, recitales y funciones teatrales - se subvierten las lógicas de las narrativas imperantes, la idílica en el caso de la novela pastoril, siendo triunfante el interés y la materialidad de las riquezas, y la realista en el caso del Quijote, siendo triunfante el amor. Santa Aguilar desarrolla y argumenta esta tesis en su detallado análisis de ambos episodios, que muestran una estructura narrativa paralela, si bien inversa.

El trabajo de Suárez Miramón trae otro de los ejes de poder y autoridad en los Siglos de Oro: el mayorazgo. Esta institución medieval, si bien fundada en un aparato teórico-teológico, generará conflictos económicos, políticos y sociales a partir ya del XVI, que se intensificarán en el XVII. No serán pocos los que la cuestionen, ya 
desde el punto de vista económico, ya desde el punto de vista de sus fundamentos teóricos. La tensión provocada por este debate se reflejará en la literatura, siendo el mayorazgo tema de muchas obras. Suárez Miramón hace un repaso por obras de varios dramaturgos principales que tratan esta cuestión, poniendo de manifiesto las diversas perspectivas desde las cuales se aborda. Se detiene en la dramaturgia calderoniana, que, más allá de los múltiples ángulos desde los que plantea el problema, revisa y reinterpreta los presupuestos sobre la primogenitura y ofrece un programa teológico-moral de resolución, señalando que la naturaleza sin méritos por obras no es suficiente.

Otro cambio ideológico se perfila en el siguiente artículo a cargo de Usunáriz, esta vez con respecto a los vínculos simbióticos de poder político y religioso, y cómo estos cambian en el lapso de un siglo, en el cual se extendió el conflicto bélico en Flandes. Para ello, se centra en dos figuras que cierran este paréntesis histórico-político, dos Guillermos, ambos protestantes, que, sin embargo, serán representados de forma distinta debido a las diferentes circunstancias en que gobierna cada uno. El primero sería una figura demonizada en España, que guerreaba bajo la bandera de defensa de la libertad de conciencia para ocultar así sus verdaderas intenciones, inspiradas por el egoísmo y la ambición. El segundo Guillermo, en la línea del primero, será, en cambio, justificado, a pesar incluso de suponer un peligro para el catolicismo. Y todo porque sobre el panorama político-bélico hay otro enemigo más peligroso: Francia. La religión, por tanto, pese a ser ideal motriz de las primeras guerras en Flandes, se ve desplazada a un segundo plano en pos de una razón puramente secular, la razón de Estado, según las necesidades políticas lo requieren. El interesante proceso que describe este artículo, se ve ilustrado casi exclusivamente por crónicas y otros documentos históricos, quedando el teatro relegado a una breve ejemplificación de la demonización del primer Guillermo.

Por último, Vega García-Luengos reúne las obras dramáticas de tema veterotestamentario de Godínez, para continuar indagando sobre representaciones del poder regio. Este interés surge por la constatación de que en todas estas piezas aparece un monarca, lo haya o no en los textos originales. Por lo demás, la gama de representación de esta figura es variada, y coincidente en el tratamiento con las tendencias críticas propias de la época. De esta forma, Vega García-Luengos hace un recorrido por el corpus de dramas veterotestamentarios, explicando los ejes básicos del argumento y desplegando las características de cada una de las figuras regias de autoridad que aparecen. Concluye que esta materia permite a Godínez dar voz a sus propias preocupaciones políticas y sociales, estrechamente vinculadas con su propia condición de converso.

En suma, el libro ofrece un interesante y variado repaso por distintos enfoques de la institución del poder y la(s) imagen(es) de la autoridad en la dramaturgia y otros textos literarios e históricos de los Siglos de Oro. La diversidad temática que engloba se ve cohesionada por el interés en el poder, cómo se manifiesta, se transmite o se problematiza, lo que, en última instancia, aporta una visión de la complejidad de la época, para nada monolítica. El panorama que ofrece, caleidoscópico, acerca sin duda al lector a las dinámicas sociales y de reflexión sobre estas a través 
del teatro, entendiéndolo también en el sentido de la teatralidad inherente a estas nociones, por lo que supone una lectura relevante y útil para todos aquellos interesados en los andamios de la cultura del Barroco. 
